\title{
Bioactivity and mechanical behaviour of cobalt oxide-doped bioactive glass
}

\author{
VIKASH KUMAR VYAS*, AREPALLI SAMPATH KUMAR, SUNIL PRASAD, S P SINGH \\ and RAM PYARE \\ Department of Ceramic Engineering, Indian Institute of Technology (Banaras Hindu University), Varanasi 221005 , India
}

MS received 25 February 2015; accepted 3 March 2015

\begin{abstract}
Bioactive glasses are materials capable of bonding implants to tissues. 45S5 Bio-glass ${ }^{\circledR}$ is one such material capable of bonding strongly to bone within 6 weeks. It develops a hydroxy-carbonate apatite layer on the implant that is chemically and crystallographically equivalent to the mineral phase of bone. However, it suffers from a mechanical weakness and low fracture toughness due to an amorphous glass network and is not suitable for load-bearing applications. In order to improve its mechanical strength and bioactivity, the present work explores the effects of cobalt oxide additions. Bioactivity of the glass samples was assessed through their hydroxyapatite formation ability by immersing them in the simulated body fluid for different soaking periods. The formation of hydroxyapatite was confirmed by Fourier transform infrared spectrometry, $\mathrm{pH}$ measurement and microstructure evaluation through scanning electron microscopy. Densities and mechanical properties of the samples were found to increase considerably with an increase in the concentration of cobalt oxide.
\end{abstract}

Keywords. Bioactive glass; cobalt oxide; FTIR spectrometry; SEM and mechanical properties.

\section{Introduction}

Some materials like bioactive glasses used for bone implant and substitutes gain major importance in view of their abilities such as the formation of new bone, ${ }^{1}$ mechanical stability ${ }^{2}$ and making free from diseases. ${ }^{3}$ First-generation biomaterials were selected to be as bio-inert as possible and thereby reduce the formation of injury tissue at the interface with foreigner tissues. In 1969 bioactive glasses were invented by Hench which shared in interfacial bonding with the surrounding tissue which was regarded as the second-generation biomaterials. Bioactive glass with the qualities of gene activation was used for tissue restoration and healing was considered to be the third generation of biomaterials. ${ }^{4}$ Hench presented the idea of a secure bonding amongst bone and synthetic material practically due to the chemical reactions taking place over glass surface. These chemical reactions strongly help bioactive glasses to form bond with the bone, thus replacing the injured or diseased bone. For this characteristic quality bioactive glass is regarded as one of the exceptionally suitable biomaterial for orthopaedic and dental applications. ${ }^{5}$ Bioactive glass usually consists of silicon, sodium, potassium, magnesium, calcium and phosphorus which are normally found to have no toxic effect on the bone cells. Many studies have revealed that in the course of bone formation and bonding by bioactive glass, the level of ion concentrations in the cell culture medium does not affect

\footnotetext{
*Author for correspondence (vkvyas.rs.cer11@itbhu.ac.in, vyas22302@rediffmail.com)
}

the surrounding tissues. ${ }^{6-9}$ Most of the published work on bioactive material is concentrated on silica-based material. It is accepted that the essential requirements for an artificial biomaterial is to exhibit the formation of apatite or calcium phosphate layer on its surface in body environment. Unlike other bioactive materials, the rate of chemical reaction of bioactive glasses can easily be controlled by changing the chemical composition and heat treatment. ${ }^{10}$ Several new bioactive glass compositions have been developed, incorporating therapeutically active ions such as strontium, ${ }^{11,12}$ zinc, ${ }^{13,14}$ cobalt, ${ }^{15}$ fluoride $^{16,17}$ and magnesium. ${ }^{18}$ Therefore bioactive silicate glasses are of interest for use as bone grafts. ${ }^{19}$ Inorganic species such as metal ions, $\mathrm{Cu}^{2+}, \mathrm{Sr}^{2+}$ and $\mathrm{Co}^{2+}$ are being considered as possible alternatives to growth factors and genetic approaches in tissue engineering because of their easy processing, stability at high temperatures and tunable release kinetics. ${ }^{20}$ In the present investigation, an attempt has been made to study the effect of cobalt oxide doping in silica-based bioactive glasses to determine its bioactivity and mechanical behaviour.

\section{Material and methods}

\subsection{Selection of composition and preparation of the bioactive glass}

The bioactive glass composition was formulated from $\mathrm{Na}_{2} \mathrm{O}-$ $\mathrm{CaO}-\mathrm{SiO}_{2}-\mathrm{P}_{2} \mathrm{O}_{5}$ glass system. Proposed bioactive glasses containing chemical composition $(45-X) \mathrm{SiO}_{2}-24.5 \mathrm{Na}_{2} \mathrm{O}-$ $24.5 \mathrm{CaO}-6 \mathrm{P}_{2} \mathrm{O}_{5}$ (where $X=0,0.5,1,1.5$ and 2 of cobalt 
oxide) were prepared. In the present study, the $\mathrm{CaO}, \mathrm{Na}_{2} \mathrm{O}$ and $\mathrm{P}_{2} \mathrm{O}_{5}$ concentration was kept constant and $\mathrm{SiO}_{2}$ was partially replaced with cobalt oxide. The compositions of prepared bioactive glasses are given in table 1 . The bioactive base glass and cobalt oxide-doped glass were prepared by the addition of cobalt oxide $(0,0.5,1,1.5$ and $2 \mathrm{~g})$ in place of $\mathrm{SiO}_{2}$ using the normal melting and annealing technique. Materials used include fine-grained quartz for silica. Lime and soda were introduced in the form of their respective anhydrous carbonates. $\mathrm{P}_{2} \mathrm{O}_{5}$ was added in the form of ammonium dihydrogen phosphate. The weighed batches were mixed thoroughly for $30 \mathrm{~min}$ and melted in a $100 \mathrm{ml}$ platinum crucibles to get the desired bioactive glass composition as given in table 1 . The melting was carried out in an electric furnace at $1400 \pm 5^{\circ} \mathrm{C}$ for $2 \mathrm{~h}$ in air as furnace atmosphere and homogenized melts were poured on preheated aluminium sheet. The prepared bioactive glass samples were directly transferred to a regulated muffle furnace at $470^{\circ} \mathrm{C}$ for annealing. After $1 \mathrm{~h}$ of annealing the muffle furnace was cooled to room temperature with controlled rate of cooling at

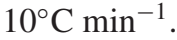

\subsection{Preparation of simulated body fluid (SBF)}

Kokubo and his colleagues developed SBF that has inorganic ion concentrations similar to those of human body fluid in order to reproduce in vitro formation of apatite on bioactive materials. ${ }^{21}$ The SBF solution was prepared by dissolving reagent-grade $\mathrm{NaCl}, \mathrm{KCl}, \mathrm{NaHCO}_{3}, \mathrm{MgCl}_{2} \cdot 6 \mathrm{H}_{2} \mathrm{O}, \mathrm{CaCl}_{2}$ and $\mathrm{KH}_{2} \mathrm{PO}_{4}$ into double distilled water and it was buffered at $\mathrm{pH}=7.4$ with trishydroxymethyl amino methane (TRIS) and $1 \mathrm{~N} \mathrm{HCl}$ at $37^{\circ} \mathrm{C}$ as compared with the human blood plasma (WBC). The ion concentrations of SBF are given in table $2 .^{21}$

\subsection{Powder X-ray diffraction (XRD) measurements}

The bioactive glass samples were ground to $75 \mu \mathrm{m}$ and the fine powders were subjected to XRD analysis using

Table 1. Composition of bioactive glasses (wt \%).

\begin{tabular}{lccccc}
\hline & $\mathrm{SiO}_{2}$ & $\mathrm{Na}_{2} \mathrm{O}$ & $\mathrm{CaO}$ & $\mathrm{P}_{2} \mathrm{O}_{5}$ & $\mathrm{CoO}$ \\
\hline $45 \mathrm{~S} 5$ & 45.00 & 24.50 & 24.50 & 6.00 & 0.00 \\
$\mathrm{CoO}-1$ & 44.50 & 24.50 & 24.50 & 6.00 & 0.50 \\
$\mathrm{CoO}-2$ & 44.00 & 24.50 & 24.50 & 6.00 & 1.00 \\
$\mathrm{CoO}-3$ & 43.50 & 24.50 & 24.50 & 6.00 & 1.50 \\
$\mathrm{CoO}-4$ & 43.00 & 24.50 & 24.50 & 6.00 & 2.00 \\
\hline
\end{tabular}

RIGAKU-Miniflex II diffractometer adopted $\mathrm{Cu}-\mathrm{K} \alpha$ radiation $(\lambda=1.5405 \AA)$ with a tube voltage of $40 \mathrm{kV}$ and current of $35 \mathrm{~mA}$ in a $2 \theta$ range between $20^{\circ}$ and $80^{\circ}$. The step size and measuring speed was set to $0.02^{\circ}$ and $1^{\prime \prime}$ per min, respectively, was used in the present investigation. The JCPDSInternational Centre for diffraction Data Cards were used as a reference.

\subsection{Structural analysis of bioactive glass by Fourier transform infrared (FTIR) reflectance spectrometry}

The structure of bioactive glass were measured at room in the frequency range of $4000-400 \mathrm{~cm}^{-1}$ using a FTIR (VARIAN scimitar 1000, USA). The fine bioactive glass powder samples were mixed with $\mathrm{KBr}$ in the ratio of $1: 100$ and the mixtures were subjected to an evocable die at load of 10 bar pressure to produce clear homogeneous discs. The prepared discs were immediately subjected to IR spectrometer to measure the reflectance spectra in order to avoid moisture attack.

\subsection{In vitro bioactivity study of bioactive glass}

In order to investigate the formation of (calcium phosphate) apatite layer on the surface of the samples after immersion in SBF solution, the sample $(1 \mathrm{~g})$ was immersed in $10 \mathrm{ml}$ of SBF solution in a small plastic container at $37^{\circ} \mathrm{C}$ with $\mathrm{pH}$ 7.40 in an incubator at static condition for the following time periods 1, 3 and 7 days. After soaking, the samples were filtered, rinsed with doubly distilled water and dried in an oven at $120^{\circ} \mathrm{C}$ for $2 \mathrm{~h}$ before analysis by FTIR and SEM.

\subsection{Mechanical behaviour measurements}

The melts were casted in rectangular shape mould and the resultant bioactive glass samples were ground and polished for required dimension using grinding machine then samples were subjected to three-point bending test. The test was performed at room temperature using Instron Universal Testing Machine (AGS 10kND, SHIMADZU) of cross-head

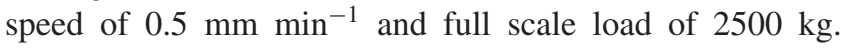
Flexural strength was determined according to ASTM Standard: C158-02 (2012). Polished bioactive glass samples were subjected to hardness testing machine the size of sample was $10 \times 10 \times 10 \mathrm{~mm}$ according to the ASTM Standard: C730-98. The indentations have been made for loads ranging between 30 and $2000 \mathrm{mN}$, applied at a velocity of $1 \mathrm{~mm} \mathrm{~s}^{-1}$ and allowed to equilibrate for $16 \mathrm{~s}$ before measurement. The densities of casted bioactive glasses were

Table 2. Ion concentration $\left(\mathrm{mM}^{-1}\right)$ of simulated body fluid and human blood plasma.

\begin{tabular}{lcccccccc}
\hline Ion & $\mathrm{Na}^{+}$ & $\mathrm{K}^{+}$ & $\mathrm{Mg}^{2+}$ & $\mathrm{Ca}^{2+}$ & $\mathrm{HCO}_{3}^{-}$ & $\mathrm{HPO}_{4}^{2-}$ & $\mathrm{SO}_{4}^{2-}$ & $\mathrm{Cl}^{-}$ \\
\hline Simulated body fluid & 142.0 & 5.0 & 1.5 & 2.5 & 4.2 & 1.0 & 0.5 & 147.8 \\
Human blood plasma & 140.0 & 5.0 & 1.5 & 2.5 & 27.0 & 1.0 & 0.5 & 103.0 \\
\hline
\end{tabular}


measured by the Archimedes principle with water as the immersion fluid. The measurements were performed at room temperature. Thin copper wire was used for immersing the samples into water. The density was determined by using ASTM: B962-14. Compressive strength of the base glass and cobalt oxide-doped bioactive glass samples having size of $3 \times 2 \times 1 \mathrm{~cm}^{-1}$ dimension according to ASTM D3171 were subjected to compression test. The test was performed using Instron Universal Testing Machine at room temperature (cross speed of $0.05 \mathrm{~cm} \mathrm{~min}^{-1}$ and full scale of $5000 \mathrm{kgf}$ ).

\section{7 pH measurement}

The $\mathrm{pH}$ of bioactive glass powder $(1 \mathrm{~g})$ was soaked in $10 \mathrm{ml}$ of SBF solution at $37^{\circ} \mathrm{C}$ for different time periods and the $\mathrm{pH}$ was measured using Universal Bio microprocessor $\mathrm{pH}$ meter. The instrument was calibrated each time with standard buffer solutions of $\mathrm{pH} 4.00$ and 7.00 at room temperature and $\mathrm{pH}$ values have been recorded during different time periods at a fixed time interval.

\subsection{Surface morphology of bioactive glass sample by SEM}

The SEM of bioactive glass powders ( $1 \mathrm{~g}$ ) were pressed (load of $10 \mathrm{MPa}$ ) into pellet form using an evocable die to produce discs of $10 \mathrm{~mm}$ in diameter. The pellets were immersed in SBF $(10 \mathrm{ml})$ for 7 days at $37^{\circ} \mathrm{C}$ and the surface morphology of samples was analysed before and after SBF treatment using a scanning electron microscope (SEM-Inspect S50, FEI). The samples were coated with gold $(\mathrm{Au})$ by sputter coating instrument before analysing SEM.

\section{Results and discussion}

\subsection{Structural analysis of bioactive glass}

The XRD patterns for base glass and cobalt oxide-doped base glass are shown in figure 1 . The observed result indicates that the glasses have amorphous structure and there is no indention for the presence of crystalline phases. It was observed that the concentration cobalt oxide increase in the composition the broad hump at $2 \theta$ between $25^{\circ}$ to $35^{\circ}$ become more intense. This may be due to the $\mathrm{Co}^{2+}$ expanding the silica network. ${ }^{22}$

Figure 2 shows the FTIR reflection spectra of the base and cobalt oxide-doped bioactive glass before SBF treatment. All the bioactive glass samples are showing similar trend behaviour, FTIR reflection spectra bands of all the glasses confirm the main characteristic of silicate network and this may be due to the presence of $\mathrm{SiO}_{2}$ as a major constituent. Therefore, the bioactive glass (CoO-1) shows the peaks 482 , $721,1028,1465$ and $3785 \mathrm{~cm}^{-1}$. The resultant IR spectra at $482 \mathrm{~cm}^{-1}$ associated with a $\mathrm{Si}-\mathrm{O}-\mathrm{Si}$ symmetric bending mode, the band at $721 \mathrm{~cm}^{-1}$ corresponds with $\mathrm{Si}-\mathrm{O}-\mathrm{Si}$ symmetric stretch of non-bridging oxygen atoms between tetrahedral. It was observed that the intensity of the band recreated as the cobalt oxide substitution in the base glass, therefore the cobalt oxide increases the nonbridging oxygen in the network. The major band at about $1028 \mathrm{~cm}^{-1}$ can be attributed to $\mathrm{Si}-\mathrm{O}-\mathrm{Si}$ stretching. The small band at 1465 $\mathrm{cm}^{-1}$ can be attributed to $\mathrm{C}-\mathrm{O}$ vibration mode. It was noticed that the intensity of the IR peak increased as the concentration of cobalt oxide increases which is due to the breaking of $\mathrm{Si}-\mathrm{O}-\mathrm{Si}$ network. The small broad band centred at about $3785 \mathrm{~cm}^{-1}$ can be assigned to hydroxyl group $(-\mathrm{OH})$ which may be the presence of adsorbed water molecules. This

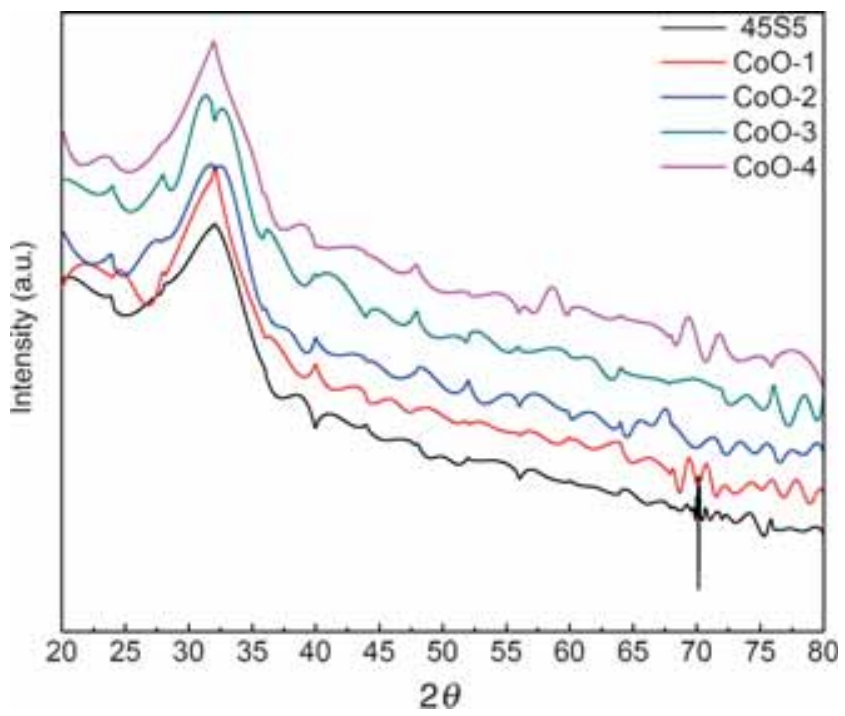

Figure 1. XRD curves of base and cobalt oxide-doped bioactive glass.

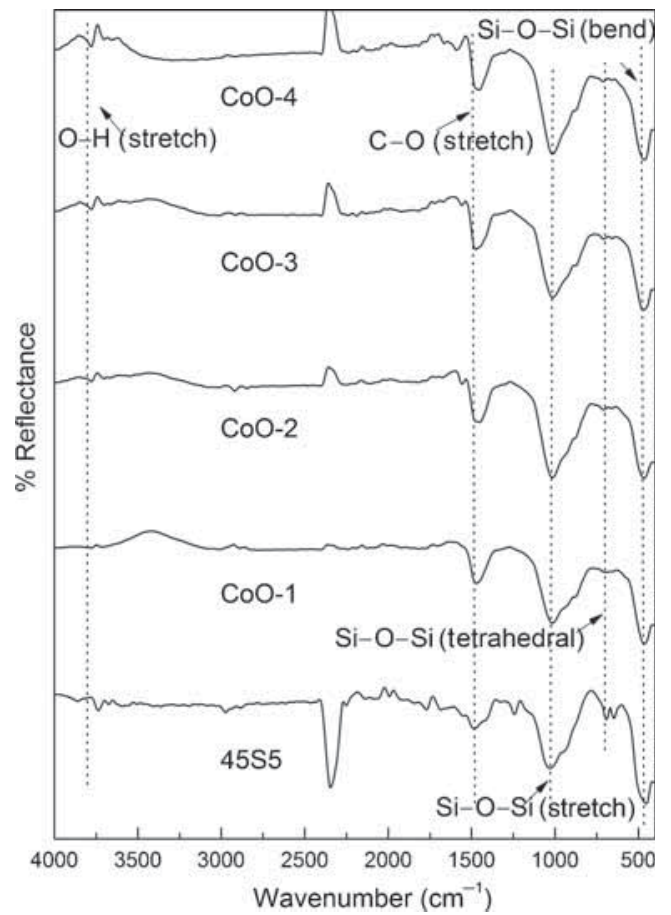

Figure 2. FTIR reflectance spectra of base and cobalt oxidedoped bioactive glasses before SBF. 
depicts the infrared frequencies and related functional structural groups in the bioactive glass. ${ }^{23}$ The bioactive glasses substituted with cobalt oxide are not showing noticeable changes in the IR spectra bands.

\section{$3.2 \mathrm{pH}$ behaviour in $\mathrm{SBF}$}

The variation in $\mathrm{pH}$ values of SBF after soaking of bioactive glasses for various time periods is shown in figure 3. It was observed that the $\mathrm{pH}$ values of all samples show the similar trend of behaviour. ${ }^{24}$ The maximum $\mathrm{pH}$ value was recorded on 3rd day of immersion. It is interesting to note that the Co-doped bioactive glasses demonstrated a higher $\mathrm{pH}$ values after immersion in SBF which is due to the fast release of cations from the surface compared with undoped sample. It was observed that due to the addition of cobalt oxide in base bioactive glass (45S5). The sequence of reactions occurred in SBF after immersion of bioactive glasses for various time periods are in favour of the formation of hydroxyl apatite like layer on the surface of the samples. ${ }^{25-27}$ In general higher is the degradation higher would be the bioactivity. Therefore the cobalt oxide-doped glasses expected to be highly bioactive. The samples number $\mathrm{CoO}-1, \mathrm{CoO}-2$ revealed highest $\mathrm{pH}$ values among the others. $\mathrm{CoO}-1$ and $\mathrm{CoO}-2$ containing 0.50 and 1.00 of cobalt oxide possessed higher $\mathrm{pH}$ and on further addition of cobalt 1.50 and 2.00 showed lower $\mathrm{pH}$ values which might have hindered the release of alkaline ions from the glass. It was reported that the transition metal ions in bioactive glasses often showed a largely controllable dissolution properties within physiological fluids and their exciting route for potential delivery systems within tissue regeneration scaffolds.

\subsection{In vitro bioactivity of bioactive glass by reflection spectroscopy}

Figures 4-8 show the FTIR reflection spectra bands of the bioactive glass before and after immersion in SBF for

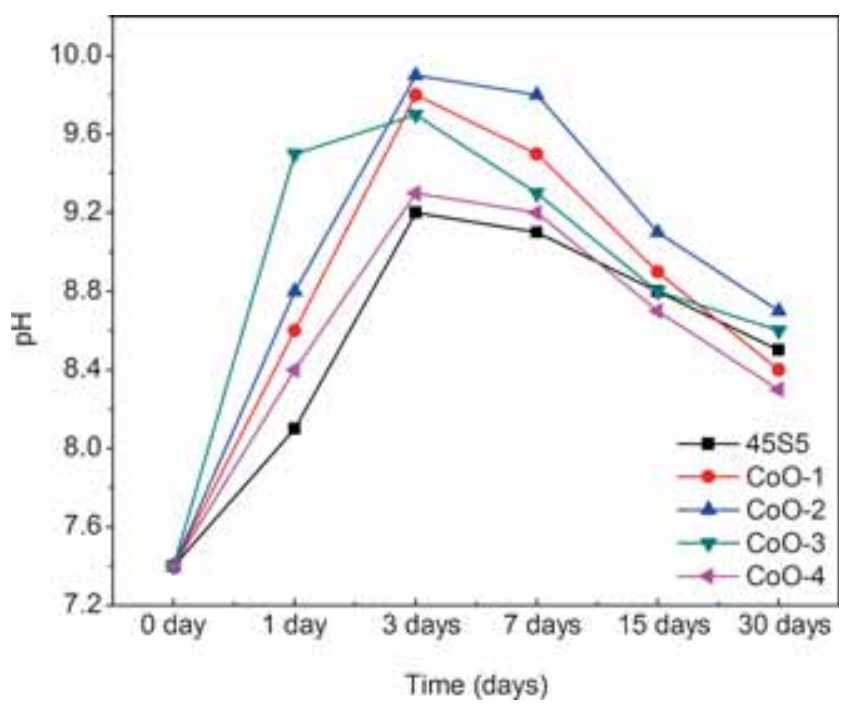

Figure 3. $\mathrm{pH}$ base and cobalt oxide-doped bioactive glass. different time periods $0,1,3$ and 7 days. Hench, ${ }^{25}$ and Rehman et $a l^{28}$ demonstrated that changes in the IR spectra bands after immersion in SBF for prolonged time period and the stages of the apatite formation on the surface of the samples after immersion in SBF.

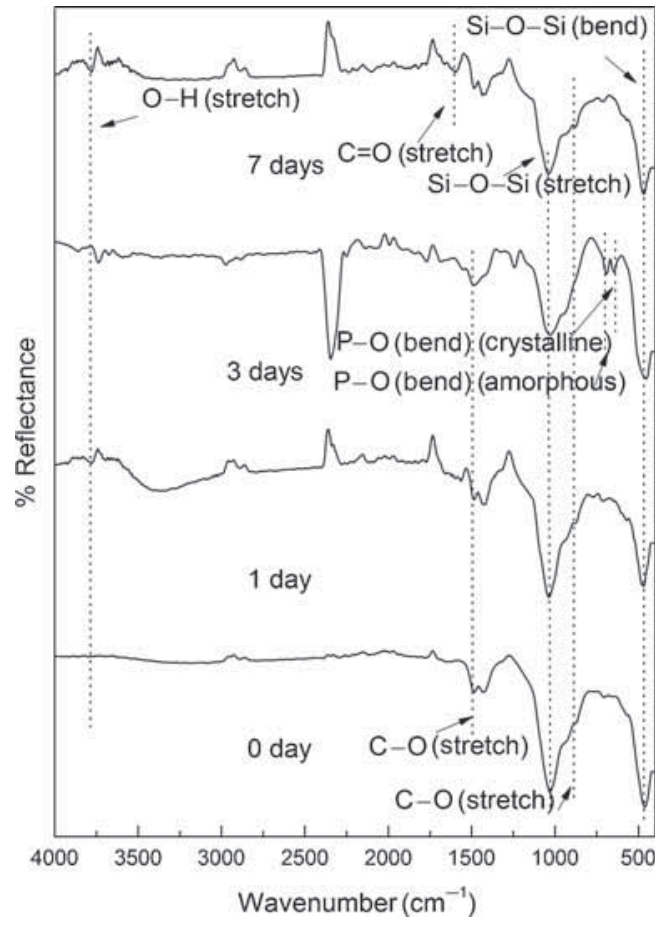

Figure 4. FTIR reflectance spectra of base bioactive glass after SBF.

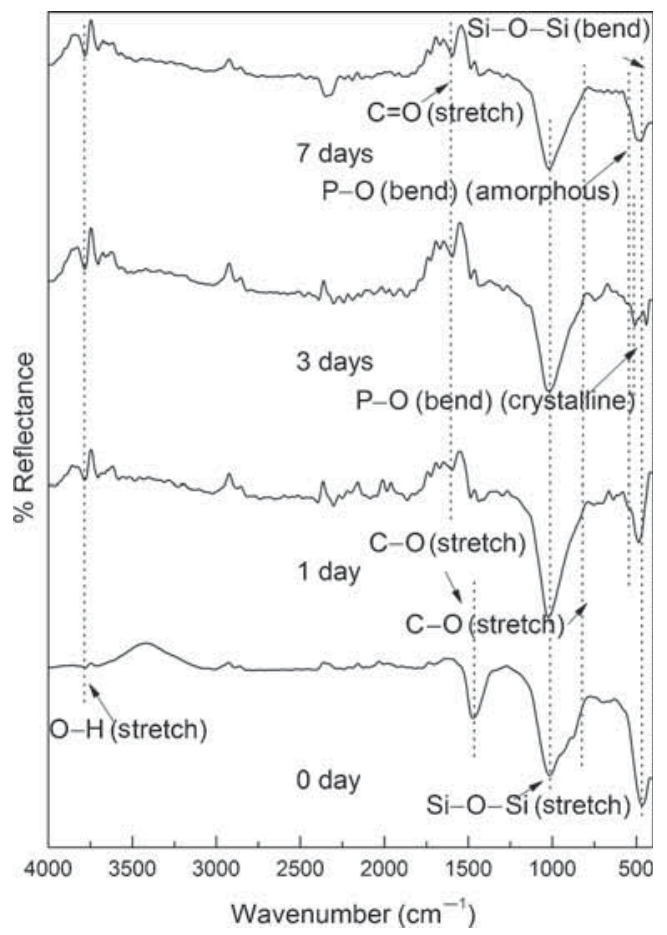

Figure 5. FTIR reflectance spectra of $\mathrm{CoO}-1$ before and after in SBF solution. 
Figure 4 shows base bioactive glass reflection spectra bands before and after immersion in SBF for different time periods 0, 1, 3 and 7 days. The new bands appearing after 1 day immersion in SBF at 591 and $631 \mathrm{~cm}^{-1}$ corresponds to $\mathrm{P}-\mathrm{O}$ bending (crystalline) and $\mathrm{P}-\mathrm{O}$ bending (amorphous), respectively, the presence of $\mathrm{C}-\mathrm{O}$ stretching $887 \mathrm{~cm}^{-1}$ band shows the crystalline nature indicating the formation of hydroxycarbonate apatite (HCA) layer. The bands at about 1495 and $1619 \mathrm{~cm}^{-1}$ are associated with $\mathrm{C}-\mathrm{O}$ (stretch) and $\mathrm{C}=\mathrm{O}$ (stretch) stretching mode and the band at about 3755 $\mathrm{cm}^{-1}$ can be assigned to (hydroxyl) $\mathrm{O}-\mathrm{H}$ groups on the surface. The prolonged period of the samples in SBF shows the same behaviour with small decrease in the intensities of the bands, which are resulted in favour of the formation of HCA layer. $^{25-27}$

Figure 5 shows the IR spectra bands of CoO-1 sample before and after treatment with SBF. The new bands appearing after 1 day immersion in SBF when compared with before immersion at 529 and $559 \mathrm{~cm}^{-1}$ corresponds to $\mathrm{P}-\mathrm{O}$ bending (crystalline) and $\mathrm{P}-\mathrm{O}$ bending (amorphous) bending, respectively, the presence of $\mathrm{C}-\mathrm{O}$ stretching $810 \mathrm{~cm}^{-1}$ band shows the crystalline nature indicating the formation of HCA layer. The bands at about 1448 and $1604 \mathrm{~cm}^{-1}$ are associated with $\mathrm{C}-\mathrm{O}$ (stretch) and $\mathrm{C}=\mathrm{O}$ (stretch) stretching mode and the broad band at about $3785 \mathrm{~cm}^{-1}$ can be assigned to (hydroxyl) O-H groups on the surface. The prolonged period of the samples in SBF shows the same behaviour with small decrease in the intensities of the bands, which are resulted in favour of the formation of HCA layer. Figure 6 shows the IR spectra bands of CoO-2 sample before and after treatments with SBF. The new bands appearing after 1 day immersion

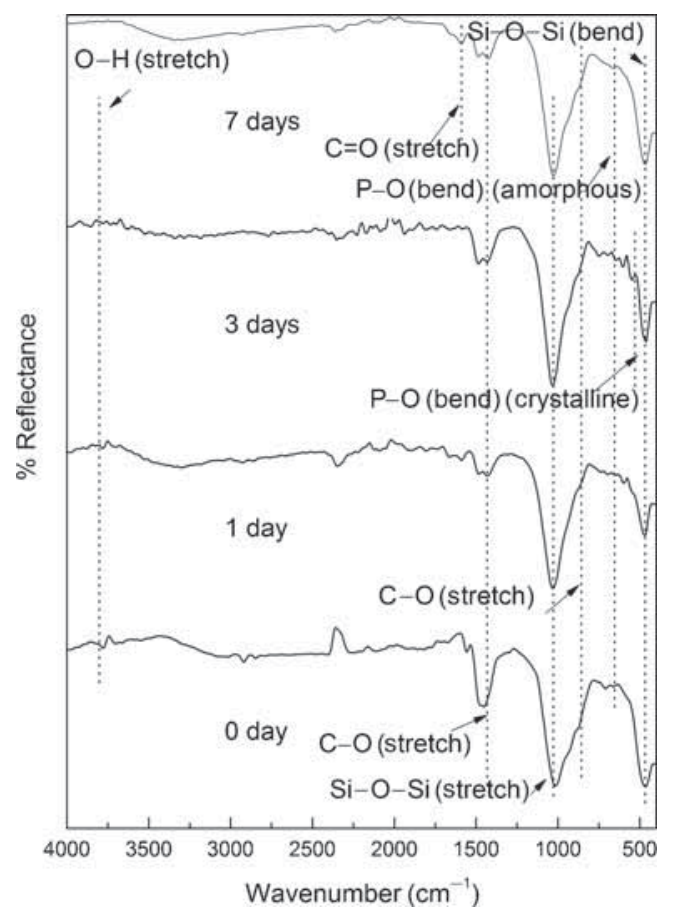

Figure 6. FTIR reflectance spectra of CoO-2 before and after in SBF solution. in $\mathrm{SBF}$ when compared with before immersion at 528 and $623 \mathrm{~cm}^{-1}$ corresponds to $\mathrm{P}-\mathrm{O}$ bending (crystalline) and $\mathrm{P}-\mathrm{O}$ bending (amorphous) bending, respectively, the presence of $\mathrm{C}-\mathrm{O}$ stretching $857 \mathrm{~cm}^{-1}$ band shows the crystalline nature indicating the formation of HCA layer. The bands at about

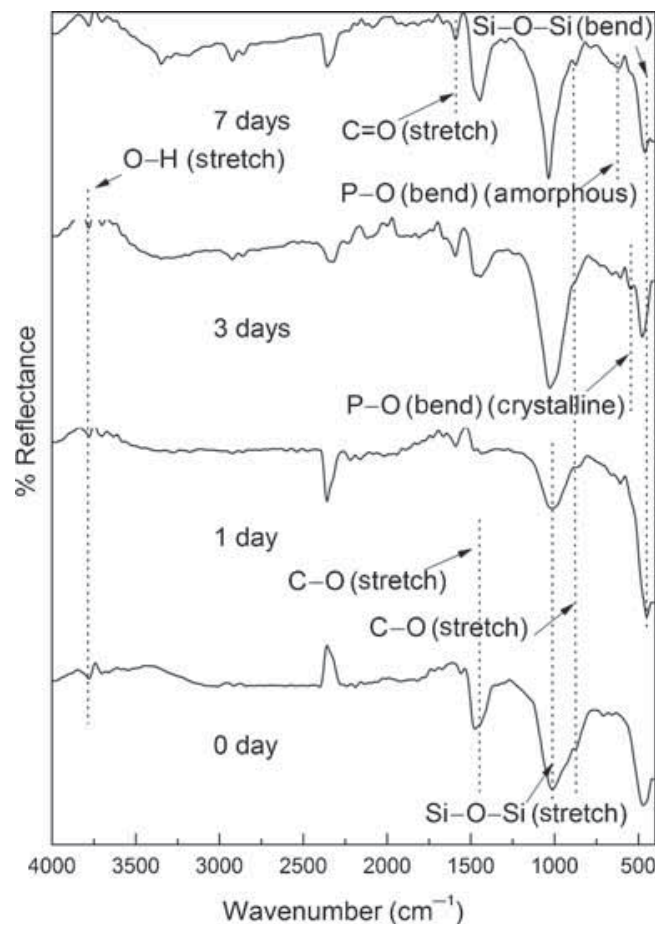

Figure 7. FTIR reflectance spectra of CoO-3 before and after in SBF solution.

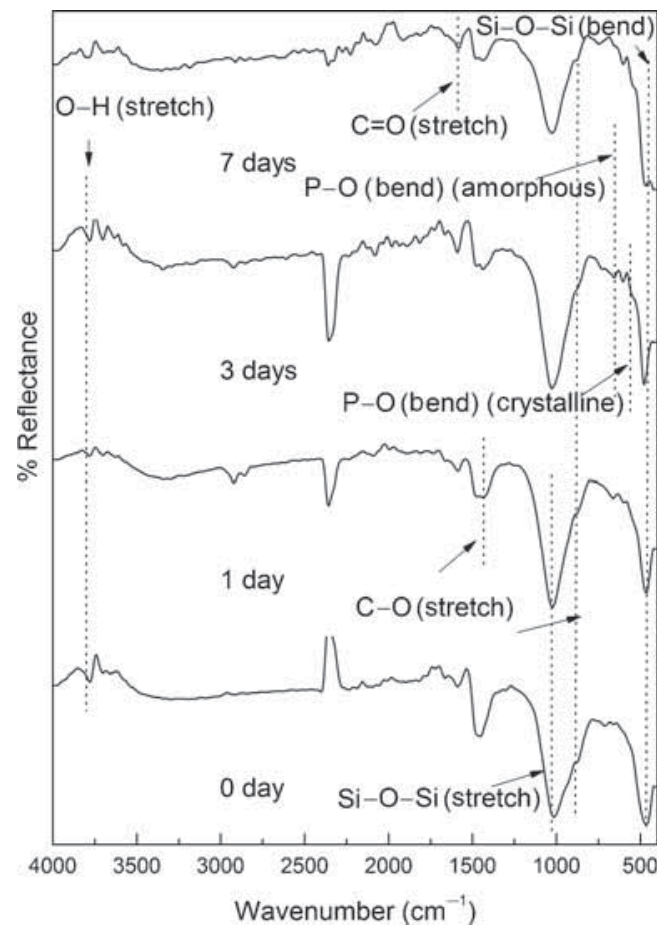

Figure 8. FTIR reflectance spectra of CoO-4 before and after in SBF solution. 
1447 and $1574 \mathrm{~cm}^{-1}$ are associated with $\mathrm{C}-\mathrm{O}$ (stretch) and $\mathrm{C}=\mathrm{O}$ (stretch) stretching mode and the broad band at about $3802 \mathrm{~cm}^{-1}$ can be assigned to (hydroxyl) $\mathrm{O}-\mathrm{H}$ groups on the surface. The prolonged period of the samples in SBF shows the same behaviour with small decrease in the intensities of the bands, which are resulted in favour of the formation of HCA layer. Figure 7 shows the IR spectra bands of CoO-3 sample before and after treatment with SBF. The new bands appearing after 1 day immersion in SBF when compared with before immersion at 529 and $607 \mathrm{~cm}^{-1}$ corresponds to $\mathrm{P}-\mathrm{O}$ bending (crystalline) and $\mathrm{P}-\mathrm{O}$ bending (amorphous) bending, respectively, the presence of $\mathrm{C}-\mathrm{O}$ stretching $872 \mathrm{~cm}^{-1}$ band shows the crystalline nature indicating the formation of HCA layer. The bands at about 1465 and $1589 \mathrm{~cm}^{-1}$ are associated with $\mathrm{C}-\mathrm{O}$ (stretch) and $\mathrm{C}=\mathrm{O}$ (stretch) stretching mode and the broad band at about $3785 \mathrm{~cm}^{-1}$ can be assigned to (hydroxyl) O-H groups on the surface. The prolonged period of the samples in SBF shows the same behaviour with small decrease in the intensities of the bands, which are resulted in favour of formation of HCA layer. Figure 8 shows the IR spectra bands of CoO-4 sample before and after treatment with SBF. The new bands appeared after 1 day immersion in SBF when compared with before immersion at 544 and $605 \mathrm{~cm}^{-1}$ corresponds to $\mathrm{P}-\mathrm{O}$ bending (crystalline) and $\mathrm{P}-\mathrm{O}$ (amorphous) bending, respectively, the presence of $\mathrm{C}-\mathrm{O}$

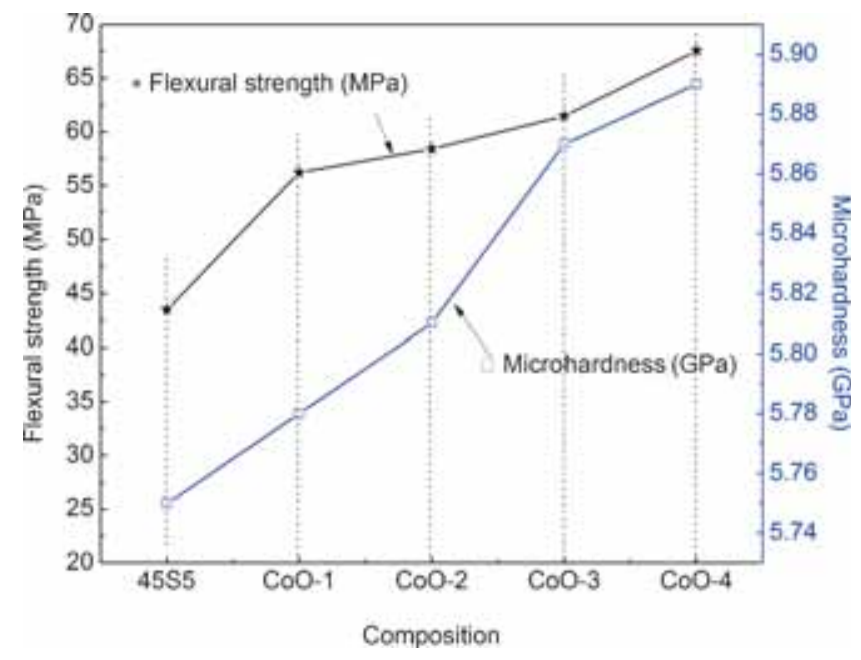

Figure 9. Flexural strength and microhardness base glass and cobalt oxide-doped glass. stretching $887 \mathrm{~cm}^{-1}$ band shows the crystalline nature indicating the formation of HCA layer. The bands at about 1433 and $1574 \mathrm{~cm}^{-1}$ are associated with $\mathrm{C}-\mathrm{O}$ (stretch) and $\mathrm{C}=\mathrm{O}$ (stretch) stretching mode and the broad band at about $3801 \mathrm{~cm}^{-1}$ can be assigned to (hydroxyl) O-H groups on the surface. The prolonged period of the samples in SBF shows the same behaviour with small decrease in the intensities of the bands, which are resulted in favour of formation of HCA layer.

\subsection{Mechanical behaviour of base and cobalt oxide-doped glass}

Figure 10 shows the density of cobalt oxide-doped 45S5 bioactive glass. It is observed that the densities of the samples were increased with the increase in the cobalt oxide content from 2.89 to $2.91 \mathrm{~g} \mathrm{~cm}^{-3}$, which may be due to partial replacement of $\mathrm{SiO}_{2}$ with $\mathrm{CoO}$, and is attributed due to the replacement of a light element (density of $\mathrm{SiO}_{2} 2.64$ ) with a heavier one ( $\mathrm{CoO} 6.11)$. Figure 9 shows the results of the flexural strength and microhardness for 45S5, CoO- 1 , CoO-2, CoO-3 and CoO-4 samples. The results demonstrate an increasing tendency in flexural strength and microhardness as the percentage of cobalt oxide $(44.48,56.25,58.42$, 61.52 and 67.72 microhardness 5.75, 5.78, 5.81, 5.87 and 5.89 , respectively). This increase may be due to the $\mathrm{Co}^{2+}$ may act as network intermediate, thus more the compactness

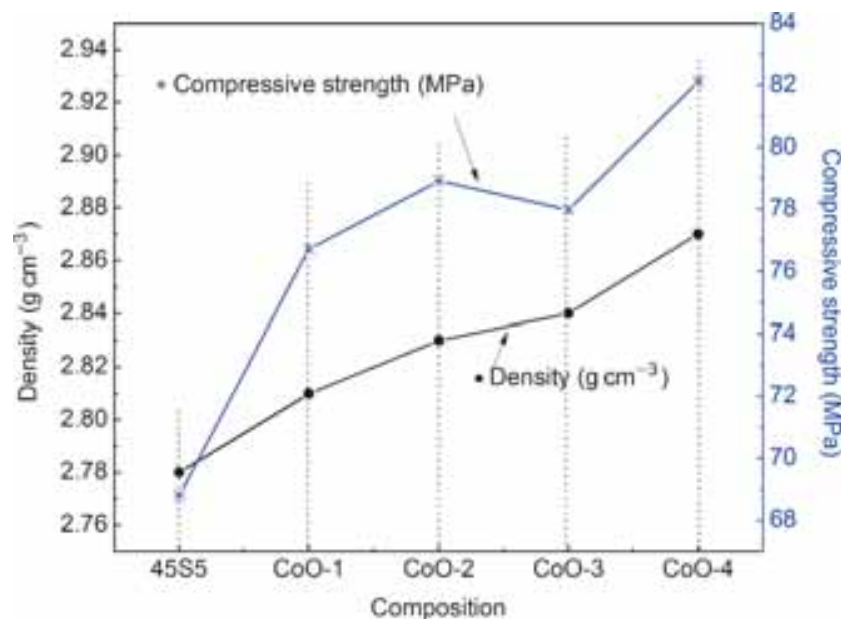

Figure 10. Density and compressive strength base glass and cobalt oxide-doped glass.

Table 3. Flexural strength, microhardness (GPa), compressive strength (MPa) and density of bioactive glass.

\begin{tabular}{lcccc}
\hline Sample & $\begin{array}{c}\text { Density }\left(\mathrm{g} \mathrm{cm}^{-3}\right) \\
\text { of glass }\end{array}$ & $\begin{array}{c}\text { Compressive } \\
\text { strength (MPa) }\end{array}$ & $\begin{array}{c}\text { Microhardness } \\
(\mathrm{GPa})\end{array}$ & $\begin{array}{c}\text { Flexural strength } \\
(\mathrm{MPa}) \text { of glass }\end{array}$ \\
\hline $45 \mathrm{~S} 5$ & 2.78 & 68.82 & 5.75 & 43.48 \\
$\mathrm{CoO}-1$ & 2.81 & 76.72 & 5.78 & 56.25 \\
$\mathrm{CoO}-2$ & 2.83 & 78.92 & 5.81 & 58.42 \\
$\mathrm{CoO}-3$ & 2.84 & 77.98 & 5.87 & 61.52 \\
$\mathrm{CoO}-4$ & 2.87 & 82.13 & 5.89 & 67.58 \\
\hline
\end{tabular}



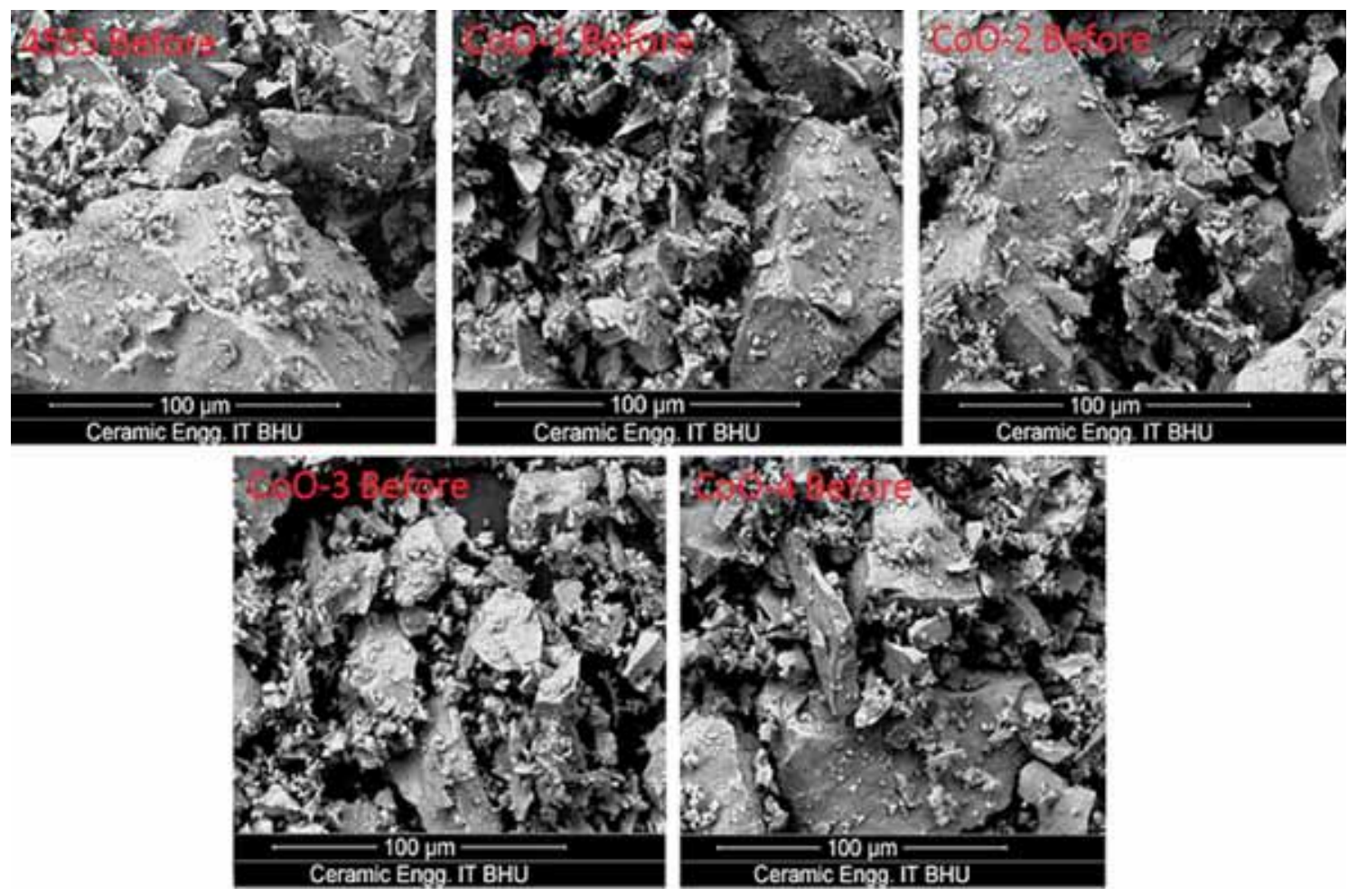

Figure 11. Scanning electron microscope (SEM) of bioactive glasses before immersion in SBF for 7 days sample 45S5, CoO-1, CoO-2, CoO-3 and CoO-4.
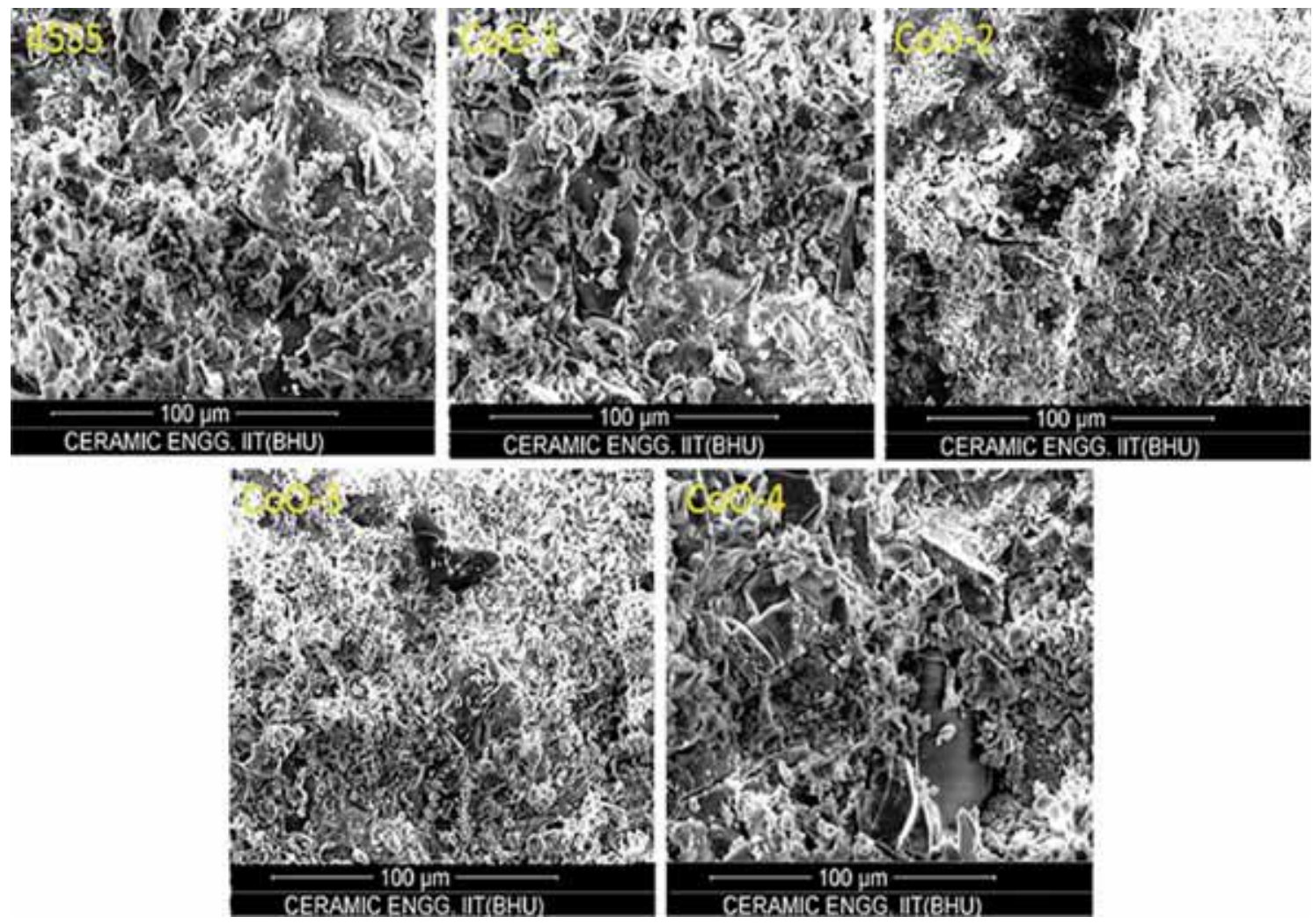

Figure 12. Scanning electron microscope (SEM) of bioactive glasses after immersion in SBF for 7 days sample 45S5, $\mathrm{CoO}-1, \mathrm{CoO}-2, \mathrm{CoO}-3$ and $\mathrm{CoO}-4$ 
of glass structure. ${ }^{29}$ This is also in agreement with density results shown in table 3 that increase in density and decrease in the volume of the glass. This can be easily understood that bioactive glass doped with cobalt oxide demonstrates more the flexural strength. Similar trend of results also found in the compressive strength $(45 \mathrm{~S} 5, \mathrm{CoO}-1 \mathrm{CoO}-2, \mathrm{CoO}-3$ and $\mathrm{CoO}-4$ and 68.82, 76.72, 78.92, 77.98 and $82.13 \mathrm{MPa}$, respectively) shown in figure 10 .

\subsection{SEM analysis of cobalt oxide-doped bioactive glass}

The SEM micrographs of base glass and cobalt oxide-doped glass samples before immersion in SBF solution are shown in figure 11 which results in different rod types of structure and asymmetrical grain of bioactive glass samples and is quite similar to result reported by Hanan et al..$^{30}$ Figure 12 represents the SEM micrographs of base glass and cobalt oxidedoped bioactive glass after immersion in SBF solution for 7 days. It is understandable from the figure 12 that base and cobalt-doped glass samples which were immersed in SBF solution for 7 days were enclosed with asymmetrical shape and grounded HA particles have been grown into more than a few agglomerates consisting of spine-shaped HA layer. These micrographs show the formation of HA on the surface of base and cobalt-doped glass samples after immersion in SBF solution for 7 days. ${ }^{31}$

\section{Conclusions}

In the present investigation, a comparative investigation was made on physico-mechanical and bioactive properties of cobalt oxide-doped 45S5 bioactive glasses. The following conclusions were drawn from this investigation. It is concluded that an increase in cobalt oxide content in this series of glasses resulted in an increase in bioactivity. This is also supported by $\mathrm{pH}$ and SEM analysis. FTIR results showed the silicate network structure in prepared bioactive glass and increasing the cobalt oxide content in 45S5 bioactive glass increases the density, flexural strength, compressive strength and microhardness.

\section{Acknowledgements}

We gratefully acknowledge the HOD, Department of Ceramic Engineering, Indian Institute of Technology (Banaras Hindu University), Varanasi 221 005, India, the honorable Director of Indian Institute of Technology (Banaras Hindu University), Varanasi, India, for providing necessary facilities for the present work.

\section{References}

1. Liu D-M 1994 Mater. Chem. Phys. 36294
2. Hench L L 1991 J. Am. Ceram. Soc. 741487

3. Buck B E, Malinin T I and Brown M D 1989 Clin. Orthop. 240 129

4. Hench L L 2006 J. Mater. Sci. Mater. Med. 17967

5. Hench L L and Clark A E 1982 In Biocompatibility of orthopaedic implants (eds) D F Williams and G D Winter (Boca Raton, Florida: CRC Press) Vol II

6. Ylänen H O 2011 Bioactive glasses: materials, properties and applications (Finland: Woodhead Publishing Limited)

7. Nakamura T, Yamamuro T Y, Tigushi S, Kokubo T and Itoo S 1985 J. Biomed. Mater. Res. 19685

8. Holand W, Vogel W, Naumann K and Gummel J 1985 J. Biomed. Mater. Res. 19303

9. Holand W and Beall G 2002 Glass-ceramic technology (Westerville, $\mathrm{OH}$ : American Ceramic Society)

10. El Batal H A, Azooz M A, Khalil E M A, Soltan Monem A and Hamdy Y M 2003 Mater. Chem. Phys. 80599

11. Fredholm Y C, Karpukhina N, Law R V and Hill R G $2010 \mathrm{~J}$. Non-Cryst. Solids 3562546

12. Gentleman E, Fredholm Y C, Jell G, Lotfibakhshaiesh N, O’Donnell M D, Hill R G et al 2010 Biomaterials 313244

13. Lusvardi G, Malavasi G, Menabue L and Menziani M C 2002 J. Phys. Chem. B 1069753

14. Aina V, Malavasi G, Pla A F, Munaron L and Morterra C 2009 Acta Biomater. 51211

15. Azevedo M M, Jell G, O’Donnell M D, Law R V, Hill R G and Stevens M M 2010 J. Mater. Chem. 208854

16. Brauer D S, Karpukhina N, O'Donnell M D, Law R V and Hill R G 2010 Acta Biomater. 63275

17. Lusvardi G, Malavasi G, Cortada M, Menabue L, Menziani M C, Pedone A et al 2008 J. Phys. Chem. B 11212730

18. Watts S J, O’Donnell M D, Law R V and Hill R G $2010 \mathrm{~J}$. Non-Cryst. Solid 356517

19. Hench L L, Splinter R J, Allen W C and Greenlee T K 1971 J. Biomed. Mater. Res. 5117

20. Mouriño V, Cattalini J P and Boccaccini A R 2012 J. R. Soc. Interface 9401

21. Kokubo T and Takadama H 2006 Biomaterials 272907

22. Gayathri Devi A V, Rajendran V and Rajendran N 2010 Mater. Chem. Phys. 124312

23. Nayak J P, Kumar S and Bera J 2010 J. Non-Cryst. Solids 356 1447

24. Cerrutia M, Greenspan D and Powers K 2005 Biomaterials 26 1665

25. Hench L L 1998 J. Am. Ceram. Soc. 811705

26. Mastelaro V R, Zanotto E D, Lequeux N and Cortes R $2000 \mathrm{~J}$. Non-Cryst. Solids 262191

27. Ducheyne P and Qiu Q 1999 Biomaterials 202287

28. Rehman I, Karsh M, Hench L L and Bonfield W $2000 \mathrm{~J}$. Biomed. Mater. Res. 5097

29. Srivastava A K and Ram Pyare 2012 J. Mater. Sci. Res. 2207

30. Beherei H H, Mohamed K R and El-Bassyouni G T 2009 Ceram. Int. 351991

31. Kokubo T, Kim H-M and Kawashita M 2003 Biomaterials 24 2161 